\title{
Drums-Alive Intervention Effect on the Motor and Functional Skills in Youth with Intellectual Disabilities and Autism Spectrum Disorder: A Pilot Study
}

\author{
Qin Yang', Jinjin Yang', Elizabeth Keener' ${ }^{1}$, Juntack $\mathbf{O h}^{3}$, \\ Agueda Gomes ${ }^{1}$, Suzanna Dillon ${ }^{1}$ \\ ${ }^{1}$ School of Health Promotion and Kinesiology, Texas Woman's University, Denton, USA \\ ${ }^{2}$ Department of Health and Movement Science, Southern Connecticut State University, New Haven, USA \\ ${ }^{3}$ Department of Physical Education, University of South Carolina, Columbia, USA \\ Email: qyang@twu.edu, yangj1@southernct.edu, ekeener1@twu.edu, \\ Juntack@mailbox.sc.edu, aguedagomes@twu.edu,sdillon@twu.edu
}

How to cite this paper: Yang, Q., Yang, J. J., Keener, E., Oh, J., Gomes, A., \& Dillon, S. (2021). Drums-Alive Intervention Effect on the Motor and Functional Skills in Youth with Intellectual Disabilities and Autism Spectrum Disorder: A Pilot Study. Advances in Physical Education, 11, 35-46.

https://doi.org/10.4236/ape.2021.111003

Received: November 10, 2020

Accepted: January 11, 2021

Published: January 14, 2021

Copyright $\odot 2021$ by author(s) and Scientific Research Publishing Inc. This work is licensed under the Creative Commons Attribution International License (CC BY 4.0).

http://creativecommons.org/licenses/by/4.0/

\begin{abstract}
Intellectual disability (ID) and autism spectrum disorder (ASD) are associated with impairments in motor development, attention, and behavior. Physical activity (PA) has been demonstrated to improve these conditions. However, many individuals with ID and ASD are not motivated to persist at performing PA tasks for an extended period of time. Therefore, there is a great need to find forms of PA that could motivate individuals to stay at performing PA. One such form of PA is Drums-Alive, which involves movement, drumming, and music to increase enjoyment motivation. While it is speculated the Drums-Alive could have an effect on motor skills, attention, and behavior, this concept has not been examined in persons with ID and ASD. Therefore, this study aimed to explore the effect of Drums-Alive on motor skills, attention, and behavior for individuals with ID and ASD. Nine adolescents diagnosed with ID or ASD participated in an eight-week Drums-Alive program intervention. Motor skills, attention, and behavior were measured before and after the intervention. Paired-samples t-tests were used, and the statistical significance was established at $p \leq 0.05$. The results suggested no significant differences in motor skills, attention, and behavior before and after the Drums-Alive intervention $(p>0.05)$. Though no statistical significance was found, improvements were observed from the pretest and posttest means, and all participants expressed their enjoyment of participating in the Drum-Alive program. More extended intervention and more participants will
\end{abstract}


be needed in future research.

\section{Keywords}

Youth, Intellectual Disabilities, Autism Spectrum Disorder, Drums-Alive, Motor Skills, Attention, Behavior

\section{Introduction}

Intellectual disability (ID) and autism spectrum disorder (ASD) are neurodevelopmental disorders characterized by impairments in motor and functional skills, which will affect daily life. Therefore, there is a great need to explore evidence-based practice to improve those skills. ID and ASD co-occur in many cases; $38 \%$ of individuals with ASD are also diagnosed with ID, which is higher than $10 \%$ of individuals with ID who are also diagnosed with ASD or as demonstrating autistic traits (Antshel et al., 2016). ID is defined by impairment of adaptive and intellectual functioning during the development period. ASD is typically characterized by developmental deficits in social skills, communication skills, and accompanying restricted, repetitive behavioral problems (America Psychiatric Association [APA], 2013). Recently, the number of people diagnosed with ID and ASD has increased dramatically. Based on the prevalence rates reported on ASD, one in 68 children were diagnosed with ASD in 2014, but the number increased to one in 54 in 2020 (Baio et al., 2018), and about one percent of the world's population has ASD (Zablotsky et al., 2015).

People with ASD and ID have established motor development delays (Lloyd et al., 2013; Staples \& Reid, 2010; Vuijk et al., 2010). Motor development delay was defined as delays refer to a person who has not gained the developmental skills expected of him or her, compared to others of the same age (SSM Health). Motor skills were characterized by stiff arms and legs, inability to bear weight in legs, problems with balance, postural stability, gait, joint flexibility, and movement speed (Jansiewicz et al., 2006; Kohen-Raz et al., 1992). Staples and Reid's (2010) research indicated that for individuals with ASD, by the age of 12, their motor function is the same as six years old typically developing children.

Functional skills are essential for daily living and for establishing the quality of life (Center for Autism Research). Specific in this current study, the function skills include attention and behavior. Attention is defined as the action of dealing with or taking special care of someone or something. Behavior is defined as the way in which one acts or conducts oneself, especially toward others, or responds to a particular situation or stimulus (Dictionary.com). However, individuals with ID and ASD often occurred with an attentional disorder, often being off-task, lacking persistence, and having difficulty sustaining focus and organization (APA, 2013). Alongside this, the prevalence of psychiatric and behavior disorders among individuals with ID compared with the general population 
is higher. The research estimated that approximately $10 \%$ to $70 \%$ of individuals demonstrate a psychiatric and behavior disturbance (Bregman, 1991). The psychiatric and behavioral disorder is also a cause of the attentional orienting problem (Murphy et al., 2017).

Physical activity (PA) has shown positive effects on the motor skills development and wellbeing of people with ID and ASD (García-Villamisar et al., 2017). $\mathrm{PA}$ as an intervention is beneficial for increasing on-task behavior and academic achievement and reducing maladaptive behavior and stereotypical behavior (Celiberti et al., 1997; Elliott et al., 1994; Oriel et al., 2011). In a free-play condition, spending more extended time and doing a moderate or moderate-vigorous physical activity has a significant and positive association with adolescent attention capacity test performance (Vanhelst et al., 2016). However, only about $21 \%$ of people met the 2008 Physical Activity Guidelines, and merely 30\% of high school students get 60 minutes of PA per week (Piercy et al., 2018). Moreover, the number of students with disabilities participating in PA is much lower when compared with their typically developing peers (Pan et al., 2011). Although the curriculum in schools for students with mental disabilities includes walking, running, ball games, swimming, and skiing, it is often difficult to motivate children with ID and ASD to participate in PA (Bodde et al., 2012). Participation in PA is often a challenge for people with ID and ASD because of poor motor functioning and low motivation (Koegel et al., 2001; Reid et al., 2003), and short attention spans. In addition, it also produces difficulties in planning and generalization (Klinger \& Renner, 2000; Ozonoff et al., 1994), and more difficulty in self-monitoring (Hughes et al., 1994). Therefore, new forms and more enjoyable PA types should be explored for students with ID and ASD with external reinforcement. The external reinforcement may motivate students to participate in an activity and may then be replaced by internal operants to promote independence (Firman et al., 2002).

Interestingly, researchers have reported that music has a positive effect on increasing on-task behavior (Dieringer et al., 2017) and decreasing off-task behavior (Titus \& Porretta, 2012) for children with ASD. Further, dance and drumming's aerobic motion can increase cardiovascular activity and oxygenation of blood (Maschi \& Bradley, 2010). Drumming and voice generate harmonic frequencies absorbed by organs, tissues, bones, and fluid that resonate with the source's expressed activity (Kalyani et al., 2011). Drumming also increases body temperature, stimulates sweat and triggers hormonal fluctuations, induces relaxation, and reduces stress and anxiety, depression, and socially resilient and aggressive behavior (Fancourt et al., 2016; Janse van Rensburg et al., 2016; Núñez, 2016). With knowledge of the positive effect of PA, music, and drumming, a program called Drums-Alive, which combines physical movement, music, and drumming, will be proposed as an intervention to improve motor skills, attention, and behavior of youth with ID and ASD.

The Drums-Alive program, developed by Carrie Ekins in 2000 in Germany 
and introduced to the United States in 2010, involves using drumsticks to strike/drum on gymnastic balls in unison along with musical rhythms and aerobic movements, dance, strength training, and some high coordination training (Dawson-Cook, 2010). Drums-Alive has been shown to produce strong physiological effects and positively influence the human immune system as well as helping Alzheimer's patients with their attention spans (Ekins et al., 2019). Additionally, as an intervention, it has improved motor performance in children and coordination and strength in children with ID (Ekins et al., 2019). However, Drums-Alive has not been used as an intervention for youth with ID and ASD targeting motor skills, attention, and behavior.

Therefore, the purpose of this study is to explore the effect of Drums-Alive intervention on motor skills, attention, and behavior for youth with ID or ASD. It is hypothesized that there will be a significant improvement in motor skills, attention, and behavior after the eight-week Drums-Alive intervention. Findings from this study will provide a direction for future research on applying Drums-Alive intervention among individuals with ID and ASD.

\section{Methods}

\subsection{Study Design}

This study applied a quasi-experimental research design to examine the effects of an eight-week Drums-Alive intervention for youth with ID and ASD. Motor skills, attention, and behavior were the three variables measured before and after the eight-week intervention.

\subsection{Participants}

A convenience sampling method was used to recruit nine youth (three girls and six boys) with ID ( $n=4)$ and ASD $(n=5)$, aged 17 to 20 years, for this study. Participants with ID were in the mild level category, while all participants with ASD require level 1 supports. All participants were receiving special education services through a public-school transition program. Participants were instructed not to participate in any types of physical activities involving music and drumming. According to the participants' individualized education program (IEP) and their school record, all of them exhibited deficits in adaptive behaviors (e.g., motor, attention, behavior). However, no participants had known sensory impairments that would inhibit drumming performance or the movements involved in the current study protocol (Drums-Alive intervention). Written consent forms were sent home to the parents or guardians of the participants, and assent forms were orally delivered to each participant on the first day of assessment. An explanation of the proposed study was included in the consent form, which required a parent's or guardian's signature before the participants were able to participate. Institutional Review Board (IRB) approval was obtained from Southern Connecticut State University (SCSU). 


\subsection{Intervention Procedures}

One week before and one week after the eight-week Drums-Alive intervention, fine and gross motor skills, attention, and behaviors were measured for all of the participants. The Drums-Alive intervention program used in this study was based on the Drums-Alive Academic-Beats program, which was specially designed for Special Olympics athletes. The intervention was delivered for 16 sessions, which were implemented at SCSU from 12:45 pm-1:45 pm every Tuesday and Thursday during the eight weeks. Each session's equipment included gymnastic balls, drumsticks, buckets, a music player, and a Drums-Alive kit. The Drums-Alive kit includes a printed copy of the Teacher's Manual (150+ lesson plans and 100+ Teacher Cue Cards) and access to the Drums Alive website with over 140 downloadable/streaming film clips and activity.

During each session, the principal investigator implemented a lesson designed to address the participants' general abilities (e.g., locomotor skills, manipulate skills, and drumming skills). All lesson plans included warm-up activities, fine motor skills with drumsticks, drumming on the stability balls combined with locomotor skills, culminating movements that combined rhythm and movement patterns, and cool-down activities. Slight changes, such as increasing the intensity or using different music, were made in each lesson according to the participants' performance and feedback.

\subsection{Instruments}

Motor skills. The Bruininks-Oseretsky Test of Motor Proficiency (2nd ed.) (BOT-2) short form (Bruininks \& Bruininks, 2005) was used to measure the participants' fine motor and gross motor skills. The reliability and validity of BOT-2 were reported with an intra-class correlation coefficient of 0.99 and an alpha of 0.92. The BOT-2 short form contains 14 items, which are separated into eight subtests: fine motor precision ( 2 items), fine motor integration ( 2 items), manual dexterity ( 1 item), bilateral coordination ( 2 items), balance ( 2 items), running speed, and agility (1 speed and agility), upper-limb coordination ( 2 items), and strength (2 items). Fine motor skill measurements were conducted in a classroom, while gross motor skill measurements were conducted in the gym-all by the principal investigator and her advisor. Each participant finished the test individually.

Attention. The Moss Attention Rating Scale (MARS) (Hart et al., 2006) was used to measure participants' attention. The MARS was originally designed as an observational rating scale to provide a reliable $(\mathrm{r}=0.64)$, quantitative, and ecologically valid measurement of attention-related behavior after traumatic brain injury (TBI) (Hart et al., 2009). This rating scale was completed by the participants' special education program director, who had been working with all participants for at least two years. The MARA uses a 5-point Likert-type scale to indicate how well statements describe the participant's behavior on 22 items. The 5 -point scale ranges from " $1=$ definitely false" to " $5=$ definitely true." All items in the scale were separated into three categories: restlessness, initiation, and con- 
sistent (Hart et al., 2006). The operational definitions of the restlessness category include: 1) Is restless or fidgety when unoccupied; 2) Persists with an activity or response after being told to stop; 3 ) Attends to nearby conversations rather than the current task or conversation; 4) Perseveres on previous topics of conversation or previous actions; and 5) Begins to touch or manipulate nearby objects not related to the task. The operational definitions of initiation category include: 1) Initiates communication with others; 2) Tends not to initiate tasks which are within his/her capabilities; and 3) Initiates activity (whether appropriate or not) without cues. The operational definition of consistent attention category include: 1) Performance is best early in the day or after a rest; 2) Speed or accuracy deteriorates over several minutes on a task but improves after a break; and 3) Performance of comparable activities is inconsistent from one day to the next (Hart et al., 2006).

Behavior. Behavior data were collected using a revised Achenbach System of Empirically Based Assessment-Children Behavior Checklist for Ages 6 - 18 (CBCL) (Achenbach \& Rescorla, 2013), which was completed by the parents/guardians. The CBCL assesses competencies, adaptive functioning, and specific behavioral problems with a total of 103 items. In this current study, a revised CBCL was used with 22 items selected from the behavioral problem section addressing social, emotional, and behavioral problems. Three selected item examples: 1) suddenly change mood or feeling; 2) Temper tantrums or hot temper; 3) Underactive, slow moving, or lacks energy. The selection of items for this revised CBCL was based on the participants' attributes and content experts' opinions. The parents/guardians rated this checklist for their child with values such as $0=$ not true (as far as you know), 1 = somewhat or sometimes true, and $2=$ very true or often true. A total score is calculated on a scale of 0 to 44 , with lower scores indicating a mild level of behavioral problems.

\subsection{Statistical Analysis}

A within-subject research design with paired T-tests was conducted to analyze the statistical mean difference between the pretest and posttest of motor skills, attention, and behavior. The statistical significance level was set up at $p \leq 0.05$. The mean and standard deviation data were used to describe both demographic and test variables. The Statistical Package for Social Sciences was used (version 25.0, SPSS IBM, Chicago, IL).

\section{Results}

\subsection{Participants Descriptive Characteristics}

Nine youth (three girls and six boys) with ID $(n=4)$ and ASD $(n=5)$ participated in this study with a mean age of 19 years old. The mean BMI was 24 $\mathrm{kg} / \mathrm{m}^{2}$, which is in the normal range for this age group of people (See Table 1).

\subsection{Paired-Samples T-Test}

This study aimed to explore the effect of an eight-week Drums-Alive program 
Table 1. Participants' demographic characteristics $(N=9)$.

\begin{tabular}{ccc}
\hline & M & SD \\
\hline Age (years) & 19 & 1.10 \\
Height $(\mathrm{cm})$ & 169 & 5.00 \\
Weight $(\mathrm{kg})$ & 59 & 9.50 \\
BMI $\left(\mathrm{kg} / \mathrm{m}^{2}\right)$ & 24 & 5.20 \\
\hline
\end{tabular}

Table 2. Pretest and posttest data on motor skills, attention, and behavior $(N=9)$.

\begin{tabular}{cccccc}
\hline & Pre-M & Post-M & Pre-SD & Post-SD & $p$ \\
Motor Skills & 46.56 & 48.11 & 20.65 & 16.07 & 0.63 \\
Attention & 50.00 & 51.00 & 5.00 & 4.60 & 0.26 \\
Behavior & 17.22 & 13.44 & 9.50 & 6.60 & 0.24 \\
\hline
\end{tabular}

on motor skills, attention, and behavior for youth with ID and ASD. It was hypothesized that there would be a significant improvement in motor skills, attention, and behavior after the eight-week Drums-Alive intervention. Paired T-tests were conducted to determine the statistical mean difference between the participants' 1) pretest and posttest in motor skills, 2) pretest and posttest in attention, and 3) pretest and posttest in behavior.

There was no significant difference in the scores for motor skills pretest $(\mathrm{M}=$ $46.56, \mathrm{SD}=20.65)$ and posttest $(\mathrm{M}=48.11, \mathrm{SD}=16.07)$ conditions; $\mathrm{t}(8)=-0.51$, $p=0.63$. There was also no significant difference in the scores for attention pretest $(M=50.00, S D=5)$ and posttest $(M=51, S D=4.6)$ conditions; $t(8)=$ $-1.21, p=0.26$. There was also no significant difference in the scores for behavior pretest $(\mathrm{M}=17.22, \mathrm{SD}=9.51)$ and posttest $(\mathrm{M}=13.44, \mathrm{SD}=6.64)$ conditions; $\mathrm{t}(8)=1.26, p=0.24$. These results suggested that the eight-week Drums-Alive intervention had no significant effect on the motor skills, attention, and behavior in youth with ID and ASD (See Table 2).

\section{Discussion}

Based on the results of the paired-samples t-test, it appeared that the eight-week Drums-Alive program intervention did improve motor skills, attention, and behavior for the nine youth with ID or ASD, but the differences were not significant. The non-significant difference in the current pilot study could be due to the small sample size, lack of a control group, short intervention period, and the variability in the participants' motor skills and behaviors. With all of these limitations, the eight-week intervention twice a week could just be too short.

The skills that the BOT-2 measures play an essential role in everyday tasks, including drawing and writing, using small objects, bouncing a ball, standing on a small balance beam, hopping on one foot, performing sit-ups, and walking and running. With a mean age of 19 years old and mean motor skills of 46.56, participants' performance of the BOT-2 fine and gross motor skills scores were 
rated well below average. Physical activities have been well reported to improve motor skills and on-task behavior for individuals with ID and ASD (Miramontez et al., 2016; Neely et al., 2015; Pan et al., 2017; Oriel et al., 2011). However, Vanhelst et al. (2016) reported that more prolonged and moderate to moderate-vigorous PA are needed in order to have positive benefits on attention capacity. McCoy et al. (2019) research suggested that adolescents with ASD were found to engage in less PA and were more likely to be overweight and obese compared with their typically developing peers. Previous research suggested that music and movement therapies are powerful tools for supporting children with ASD in developing communication, expression, and motor skills (Ragone, 2020). However, sometimes motor difficulties can limit individuals with ID and ASD to participate in PA. Sefen et al. (2020) research on the beneficial use and potential effectiveness of PA in managing ASD suggested that in terms of PA programs and behavior interventions, each person with ASD has a highly individualized set of symptoms and characteristics that require highly individualized plans.

Interestingly, though no statistical significance was seen on three variables in the current study, the Drums-Alive intervention process did bring a lot of enjoyment to the participants. All participants expressed their love for the DrumsAlive program and could stay on task for a longer duration of the Drums-Alive program and follow the instructor's director drumming with music. Feedback from the participants' director showed that all participants were motivated to do more PA after the eight-week intervention. In the field of adapted physical education, the practical significance is equally crucial as statistical significance.

Therefore, the Drums-Alive program should still be encouraged to be implemented in youth with ID and ASD to increase the motivation and enjoyment in participating in physical activity programs.

\section{Conclusion}

Based on the current pilot study results, it appears that Drums-Alive as an intervention did not significantly improve the motor skills, attention, and behavior of youth with ID or ASD, but all participants loved the Drums-Alive program when it combined movement, music, and drumming together. It is hard to improve motor skills, attention, and behavior for youth with ID and ASD. This pilot study could encourage further research in this area, emphasizing extending the intervention's duration and intensity with a larger population at a younger age. Early interventions are crucial in human motor and functional skills development. Future research can also consider examining variables, such as enjoyment, social skills, and motivation in physical activity participation, based on this pilot study.

\section{Acknowledgments}

This study was supported by Southern Connecticut State University in the United States. Special thanks to my thesis advisors, Drs. Jinjin Yang and David Kamler. 
Thanks also to my doctoral advisor, Dr. Suzanna Dillon. We are also very grateful to all participants and their program directors, Mr. Usuzawa, and his colleagues. The authors gratefully acknowledge support from the Texas Woman's University Center for Student Research for publication fees.

\section{Conflicts of Interest}

The authors declare no conflicts of interest regarding the publication of this paper.

\section{References}

Achenbach, T., \& Rescorla, L. (2013). Achenbach System of Empirically Based Assessment (pp. 31-39). New York, NY: Springer.

https://doi.org/10.1007/978-1-4419-1698-3_219

American Psychiatric Association (2013). Diagnostic and Statistical Manual of Mental Disorders (5th ed.). Washington DC: American Psychiatric Publishing. https://doi.org/10.1176/appi.books.9780890425596

Antshel, K. M., Zhang-James, Y., Wagner, K. E., Ledesma, A., \& Faraone, S. V. (2016). An Update on the Comorbidity of ADHD and ASD: A Focus on Clinical Management. Expert Review of Neurotherapeutics, 16, 279-293. https://doi.org/10.1586/14737175.2016.1146591

Baio, J., Wiggins, L., Christensen, D. L., Maenner, M. J., Daniels, J., Warren, Z., \& Durkin, M. S. (2018). Prevalence of Autism Spectrum Disorder among Children Aged 8 Years-Autism and Developmental Disabilities Monitoring Network, 11 Sites, United States, 2014. MMWR Surveillance Summaries, 676, 1.

https://doi.org/10.15585/mmwr.ss6706a1

Bodde, A. E., Seo, D. C., Frey, G. C., Lohrmann, D. K., \& Van Puymbroeck, M. (2012). Developing a Physical Activity Education Curriculum for Adults with Intellectual Disabilities. Health Promotion Practice, 13, 116-123. https://doi.org/10.1177/1524839910381698

Bregman, J. D. (1991). Current Developments in the Understanding of Mental Retardation Part II: Psychopathology. Journal of the American Academy of Child \& Adoles cent Psychiatry, 30, 861-872. https://doi.org/10.1097/00004583-199111000-00001

Bruininks, R., \& Bruininks, B. D. (2009). Bruininks-Oseretsky Test of Motor Proficiency (2nd ed.). Minneapolis, MN: NCS Pearson. https://doi.org/10.1037/t14992-000

Celiberti, D. A., Bobo, H. E., Kelly, K. S., Harris, S. L., \& Handleman, J. S. (1997). The Differential and Temporal Effects of Antecedent Exercise on the Self-Stimulatory Behavior of a Child with Autism. Research in Developmental Disabilities, 18, 139-150. https://doi.org/10.1016/S0891-4222(96)00032-7

Dawson-Cook, S. (2010). Drums Alive ${ }^{\circledast}$. American Fitness, 28, 42.

Dieringer, S. T., Porretta, D. L., \& Sainato, D. (2017). Music and On-Task Behaviors in Preschool Children with Autism Spectrum Disorder. Adapted Physical Activity Quarterly, 34, 217-234. https://doi.org/10.1123/apaq.2015-0033

Ekins, C., Boehr, J., Schulz, H., Wright, P. R., Owens, D., \& Miller, W. (2019). Effects of a Drums Alive ${ }^{\circledast}$ Kids Beats Intervention on Motor Skills and Behavior in Children with Intellectual Disabilities. Palaestra, 33, 16-25. 
Elliott, R. O., Dobbin, A. R., Rose, G. D., \& Soper, H. V. (1994). Vigorous, Aerobic Exercise versus General Motor Training Activities: Effects on Maladaptive and Stereotypic Behaviors of Adults with Both Autism and Mental Retardation. Journal of Autism and Developmental Disorders, 24, 565-576. https://doi.org/10.1007/BF02172138

Fancourt, D., Perkins, R., Ascenso, S., Carvalho, L. A., Steptoe, A., \& Williamon, A. (2016). Effects of Group Drumming Interventions on Anxiety, Depression, Social Resilience, and Inflammatory Immune Response among Mental Health Service Users. PLoS ONE, 11, e0151136. https://doi.org/10.1371/journal.pone.0151136

Firman, K. B., Beare, P., \& Loyd, R. (2002). Enhancing Self-Management in Students with Mental Retardation: Extrinsic versus Intrinsic Procedures. Education and Training in Mental Retardation and Developmental Disabilities, 37, 163-171.

García-Villamisar, D., Dattilo, J., \& Muela, C. (2017). Effects of Therapeutic Recreation on Adults with ASD and ID: A Preliminary Randomized Control Trial. Journal of Intellectual Disability Research, 61, 325-340.

Hart, T., Whyte, J., Ellis, C., \& Chervoneva, I. (2009). Construct Validity of an Attention Rating Scale for Traumatic Brain Injury. Neuropsychology, 23, 729-35. https://doi.org/10.1037/a0016153

Hart, T., Whyte, J., Millis, S., Bode, R., Malec, J., Richardson, R. N., \& Hammond, F. (2006). Dimensions of Disordered Attention in Traumatic Brain Injury: Further Validation of the Moss Attention Rating Scale. Archives of Physical Medicine and Rehabilitation, 87, 647-655. https://doi.org/10.1016/j.apmr.2006.01.016

Hughes, C., Russell, J., \& Robbins, T. W. (1994). Evidence for Executive Dysfunction in Autism. Neuropsychologia, 32, 477-492. https://doi.org/10.1016/0028-3932(94)90092-2

Janse van Rensburg, E., Hatting, R., van Rooyen, C. M., Chelin, M. B., van der Merwe, C., \& Putter, L. (2016). The Short Term Effect of a Group Drumming Intervention on Aggressive Behavior among Adolescent Girls Diagnosed with Conduct Disorder. South African Journal of Occupational Therapy, 46, 16-22. http://dx.doi.org/10.17159/2310-3833/2016/v46n2a4

Jansiewicz, E. M., Goldberg, M. C., Newschaffer, C. J., Denckla, M. B., Landa, R., \& Mostofsky, S. H. (2006). Motor Signs Distinguish Children with High Functioning Autism and Asperger's Syndrome from Controls. Journal of Autism and Developmental Disorders, 36, 613-621. https://doi.org/10.1007/s10803-006-0109-y

Kalyani, D., McMurtrey, K. B., Neufeldt, S. R., \& Sanford, M. S. (2011). Room-Temperature C-H Arylation: Merger of Pd-Catalyzed C-H Functionalization and Visible-Light Photocatalysis. Journal of the American Chemical Society, 133, 18566-18569.

https://doi.org/10.1021/ja208068w

Klinger, L. G., \& Renner, P. (2000). Performance-Based Measures in Autism: Implications for Diagnosis, Early Detection, and Identification of Cognitive Profiles. Journal of Clinical Child Psychology, 29, 479-492. https://doi.org/10.1207/S15374424JCCP2904_3

Koegel, R. L., Koegel, L. K., \& McNerney, E. K. (2001). Pivotal Areas in Intervention for Autism. Journal of Clinical Child Psychology, 30, 19-32. https://doi.org/10.1207/S15374424JCCP3001_4

Kohen-Raz, R., Volkman, F. R., \& Cohen, D. J. (1992). Postural Control in Children with Autism. Journal of Autism and Developmental Disorders, 22, 419-432. https://doi.org/10.1007/BF01048244

Lloyd, M., MacDonald, M., \& Lord, C. (2013). Motor Skills of Toddlers with Autism Spectrum Disorders. Autism, 17, 133-146. 
https://doi.org/10.1177/1362361311402230

Maschi, T., \& Bradley, C. (2010). Recreational Drumming: A Creative Arts Intervention Strategy for Social Work Teaching and Practice. Journal of Baccalaureate Social Work, 15, 53-66.

McCoy, S. M., \& Morgan, K. (2020). Obesity, Physical Activity, and Sedentary Behaviors in Adolescents with Autism Spectrum Disorder Compared with Typically Developing Peers. Autism, 24, 387-399. https://doi.org/10.1177/1362361319861579

Miramontez, S. K., \& Schwartz, I. S. (2017). The Effects of Physical Activity on the On-Task Behavior of Young Children with Autism Spectrum Disorders. International Electronic Journal of Elementary Education, 9, 405-418.

Murphy, E. R., Norr, M., Strang, J. F., Kenworthy, L., Gaillard, W. D., \& Vaidya, C. J. (2017). Neural Basis of Visual Attentional Orienting in Childhood Autism Spectrum Disorders. Journal of Autism and Developmental Disorders, 47, 58-67. https://doi.org/10.1007/s10803-016-2928-9

Neely, L., Rispoli, M., Gerow, S., \& Ninci, J. (2015). Effects of Antecedent Exercise on Academic Engagement and Stereotypy during Instruction. Behavior Modification, 39, 98-116. https://doi.org/10.1177/0145445514552891

Núñez, S. (2016). Medicinal Drumming: An Ancient and Modern-Day Healing Approach. NeuroQuantology, 14, 226-241. http://dx.doi.org/10.14704/nq.2016.14.2.939

Oriel, K. N., George, C. L., Peckus, R., \& Semon, A. (2011). The Effects of Aerobic Exercise on Academic Engagement in Young Children with Autism Spectrum Disorder. Pediatric Physical Therapy, 23, 187-193. https://doi.org/10.1097/PEP.0b013e318218f149

Ozonoff, S., Strayer, D. L., McMahon, W. M., \& Filloux, F. (1994). Executive Function Abilities in Autism and Tourette Syndrome: An Information Processing Approach. Journal of Child Psychology and Psychiatry, 35, 1015-1032.

Pan, C. Y., Chang, Y. K., Tsai, C. L., Chu, C. H., Cheng, Y. W., \& Sung, M. C. (2017). Effects of Physical Activity Intervention on Motor Proficiency and Physical Fitness in Children with ADHD: An Exploratory Study. Journal of Attention Disorders, 21, 783-795. https://doi.org/10.1177/1087054714533192

Pan, C. Y., Tsai, C. L., \& Hsieh, K. W. (2011). Physical Activity Correlates for Children with Autism Spectrum Disorders in Middle School Physical Education. Research Quarterly for Exercise and Sport, 82, 491-498.

https://doi.org/10.1080/02701367.2011.10599782

Piercy, K. L., Troiano, R. P., Ballard, R. M., Carlson, S. A., Fulton, J. E., Galuska, D. A., George, S. M., \& Olson, R. D. (2018). The Physical Activity Guidelines for Americans. Journal of the American Medical Association, 320, 2020-2028.

Ragone, G. (2020). Designing Embodied Musical Interaction for Children with Autism. In The 22nd International ACM SIGACCESS Conference on Computers and Accessibility (pp. 1-4). New York, NY: Association for Computing Machinery. https://doi.org/10.1145/3373625.3417077

Reid, G., O’Connor, J., \& Lloyd, M. (2003). The Autism Spectrum Disorders: Physical Activity Instruction-Part III. Palaestra, 19, 20-26.

Sefen, J. A. N., Al-Salmi, S., Shaikh, Z., AlMulhem, J. T., Rajab, E., \& Fredericks, S. (2020). Beneficial Use and Potential Effectiveness of Physical Activity in Managing Autism Spectrum Disorder. Frontiers in Behavioral Neuroscience, 14, Article ID: 587560. https://doi.org/10.3389/fnbeh.2020.587560

Staples, K. L., \& Reid, G. (2010). Fundamental Movement Skills and Autism Spectrum 
Disorders. Journal of Autism and Developmental Disorders, 40, 209-217.

https://doi.org/10.1007/s10803-009-0854-9

Titus, S., \& Porretta, D. L. (2012). Using Music to Decrease Off-Task Behavior for Children with Autism. Research Quarterly for Exercise and Sport, 83, Article No. A-91.

Vanhelst, J., Béghin, L., Duhamel, A., Manios, Y., Molnar, D., De Henauw, S. et al. (2016). Physical Activity Is Associated with Attention Capacity in Adolescents. The Journal of Pediatrics, 168, 126-131.E2. https://doi.org/10.1016/j.jpeds.2015.09.029

Vuijk, P. J., Hartman, E., Scherder, E., \& Visscher, C. (2010). Motor Performance of Children with Mild Intellectual Disability and Borderline Intellectual Functioning. Journal of Intellectual Disability Research, 54, 955-965.

Zablotsky, B., Black, L. I., Maenner, M. J., Schieve, L. A., \& Blumberg, S. J. (2015). Estimated Prevalence of Autism and Other Developmental Disabilities Following Questionnaire Changes in the 2014 National Health Interview Survey. National Health Statistics Reports, No. 87, 1-20. https://pubmed.ncbi.nlm.nih.gov/26632847/ 